OPEN ACCESS

Edited by:
Zexing Cao,
Xiamen University, China

Reviewed by:

Chunsen Li,

Fujian Institute of Research on the

Structure of Matter (CAS), China

Xinzheng Yang,

Institute of Chemistry (CAS), China

Wei Guan,

Northeast Normal University, China

*Correspondence:

Hujun Xie

hujunxie@gmail.com

Specialty section:

This article was submitted to

Theoretical and Computational

Chemistry,

a section of the journal

Frontiers in Chemistry

Received: 11 January 2019

Accepted: 05 March 2019

Published: 27 March 2019

Citation:

Ying $F$, Zhang $Y$, Xiang $C$, Song $Z$, Xie H and Bao W (2019) Key

Mechanistic Features in

Palladium-Catalyzed

Methylcyclopropanation of

Norbornenes With Vinyl Bromides: Insights From DFT Calculations.

Front. Chem. 7:169.

doi: 10.3389/fchem.2019.00169

\section{Key Mechanistic Features in Palladium-Catalyzed Methylcyclopropanation of Norbornenes With Vinyl Bromides: Insights From DFT Calculations}

\author{
Fang Ying ${ }^{1,2}$, Yutong Zhang ${ }^{1}$, Chuyue Xiang ${ }^{1}$, Zhijun Song ${ }^{1}$, Hujun Xie ${ }^{1 *}$ and Weiliang Bao ${ }^{3}$ \\ ${ }^{1}$ Department of Applied Chemistry, Zhejiang Gongshang University, Hangzhou, China, ${ }^{2}$ Hangzhou Environmental Monitoring \\ Center Station, Hangzhou, China, ${ }^{3}$ Department of Chemistry, Zhejiang University, Hangzhou, China
}

DFT calculations were performed to elucidate mechanistic details of an unusual palladium-catalyzed methylcyclopropanation from $[2+1]$ cycloadditions of (Z)-2-bromovinylbenzene and endo- $\mathrm{N}$-(p-tolyl)-norbornenesuccinimide. The reaction proceeds via oxidative addition $(\mathrm{OA})$, intermolecular alkene insertion, deprotonation/protonation, intramolecular alkene insertion, $\beta-\mathrm{H}$ elimination and reductive elimination $(\mathrm{RE})$. Protonation is the rate-limiting step and requires an overall barrier of $28.5 \mathrm{kcal} / \mathrm{mol}$. The sources of two protons for protonation and exchange have also been clarified and the calculations agree with experimental observations.

Keywords: Pd catalysis, DFT calculation, cycloaddition, mechanism, protonation

\section{INTRODUCTION}

Cyclopropane skeleton has attracted tremendous attention from organic chemists and can be found in many important biomolecules and pharmaceutical drugs (Hofmann et al., 1954; Crowley et al., 1961; Wiberg, 1996; de Meijere, 2003; Fedorynski, 2003; Lebel et al., 2003; Pietruszka, 2003; Reissig and Zimmer, 2003; Wessjohann et al., 2003; Hata et al., 2011; Chen et al., 2014; Hiratsuka et al., 2014). Many methods have been used to construct the cyclopropane scaffold, including transition metal mediated C-C and C-H bond activations (Satake and Nakata, 1998; Goudreau and Charette, 2010; Oonishi et al., 2012; Masutomi et al., 2014; Du et al., 2015), carbene/carbenoid cycloadditions (Miki et al., 2002; Biswas et al., 2012; Lindsay et al., 2013), Simmons-Smith reactions (Simmons and Smith, 1958; Beaulieu et al., 2013), Michael-initiated ring closure (MIRC) (Xie et al., 2007; Xuan et al., 2009), cycloisomerizations (Bruneau, 2005; Miege et al., 2011), and the coupling of norbornenes with organoboron reagents or alkynes (Bigeault et al., 2005; Miura et al., 2006).

However, the cyclopropanation of halohydrocarbon with alkenes catalyzed by transition metal catalysts by a non-carbene mechanism is still underdeveloped (Mao and Bao, 2014a; Mao et al., 2014). Recently, we firstly reported the palladium-catalyzed methylcyclopropanation of bromostyrenes with norbornenes via $[2+1]$ cycloaddition, and the reactions proceed by a methylene protonation and a $\mathrm{H} / \mathrm{D}$ exchange with $\mathrm{CD}_{3} \mathrm{OD}$ (Mao et al., 2015). A methylcyclopropane group was constructed through a three-fold domino method including an important protonation 


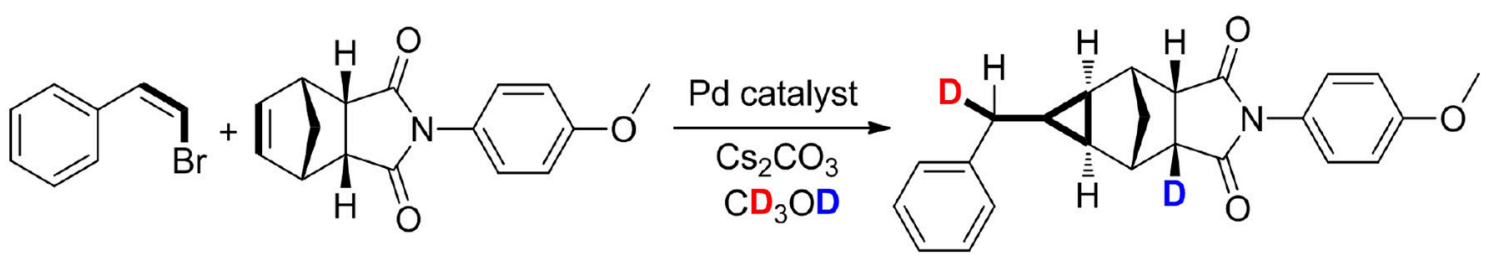

GRAPHICAL ABSTRACT | Palladium-Catalyzed Methylcyclopropanation of Norbornenes With Vinyl Bromides.

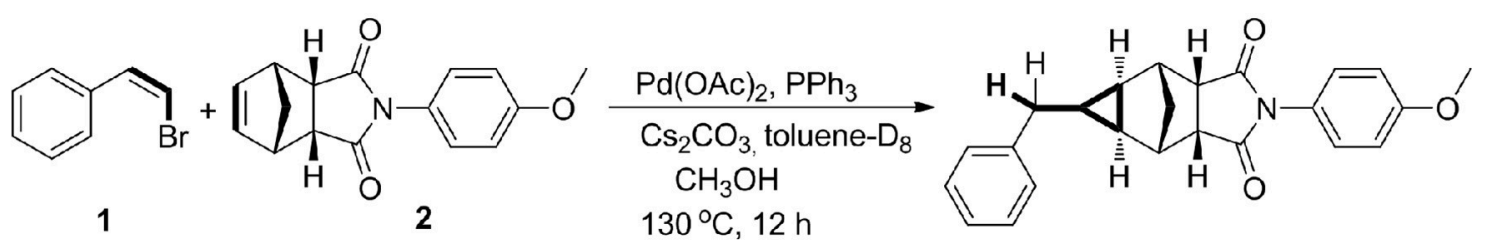

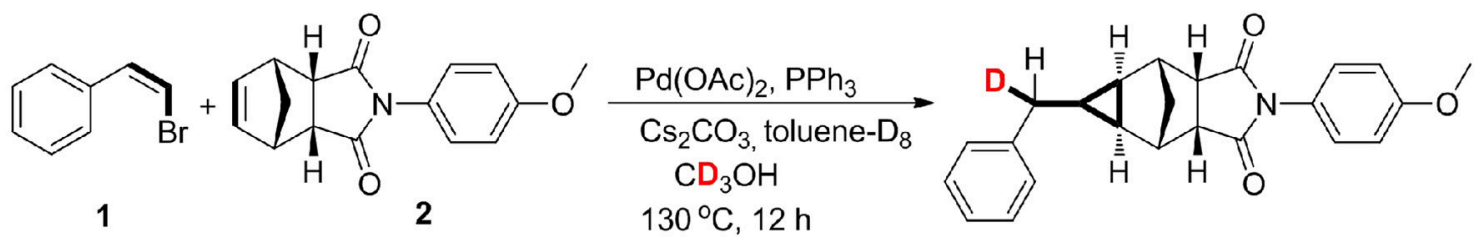

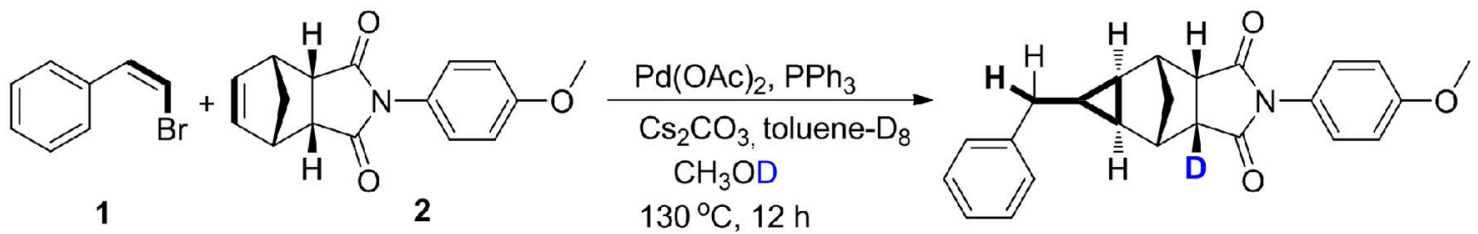<smiles>[2H]C([2H])([2H])C([2H])([2H])[2H]</smiles>

SCHEME 1 | Deuterium-labeling studies.

process. The experimental results demonstrated that a norbornenylpalladium intermediate could capture one proton from research systems (Palucki et al., 1997; Torraca et al., 2000; Kuwabe et al., 2001; Matsukawa et al., 2005; Tseng et al., 2006; Dash and Janni, 2012; Mao and Bao, 2014b). The mechanistic studies revealed that the methylcyclopropanation step proceeds via a protonation and a $\mathrm{H} / \mathrm{D}$ exchange with $\mathrm{CD}_{3} \mathrm{OD}$. As shown in Scheme 1, two different deuterium atoms from $\mathrm{CD}_{3} \mathrm{OD}$ were chemoselectively added into the two positions of methylcyclopropane derivatives. Herein, quantum chemistry (QC) calculations have been used to elucidate the reaction mechanisms, and the protonation step and a H/D exchange process from $\mathrm{CD}_{3} \mathrm{OD}$ have also been explored and discussed.

\section{COMPUTATIONAL METHODS}

All of species were optimized through M06 functional (Zhao and Truhlar, 2006a,b, 2008) in combination with 6-31G(d,p) basis set for $\mathrm{H}, \mathrm{C}, \mathrm{O}$ and $\mathrm{N}$ atoms. The $\mathrm{Pd}, \mathrm{P}, \mathrm{Br}$, and $\mathrm{Cs}$ atoms were described by LANL2DZ basis set (Ehlers et al., 1993; Check et al., 2001). The polarization functions involving $\operatorname{Pd}\left(\zeta_{\mathrm{f}}\right)=1.472$ (Huzinaga, 1984), $\operatorname{Br}\left(\zeta_{\mathrm{d}}\right)=0.389, \mathrm{P}\left(\zeta_{\mathrm{d}}\right)=0.340$, and $\mathrm{Cs}\left(\zeta_{\mathrm{f}}\right)=0.306$ were also added (Amatore et al., 1992). The structural parameters of complex $\mathbf{1}$ from calculations are consistent with the measured parameters from experiments (Figure 1; Mao et al., 2015) suggesting that the computational method in our calculations is right. Frequency analyses have been used to obtain the zero-point energies (ZPE), and then confirmed the transition states with only one imaginary frequency and the intermediates with zero imaginary frequency. Each transition state was also validated through intrinsic reaction coordinate calculations to connect the reactant and product (Fukui, 1970, 1981). Natural bond orbital (NBO) was carried out to obtain atomic charge distribution (Reed and Weinhold, 1985; Reed et al., 1985, 1988). In order to 


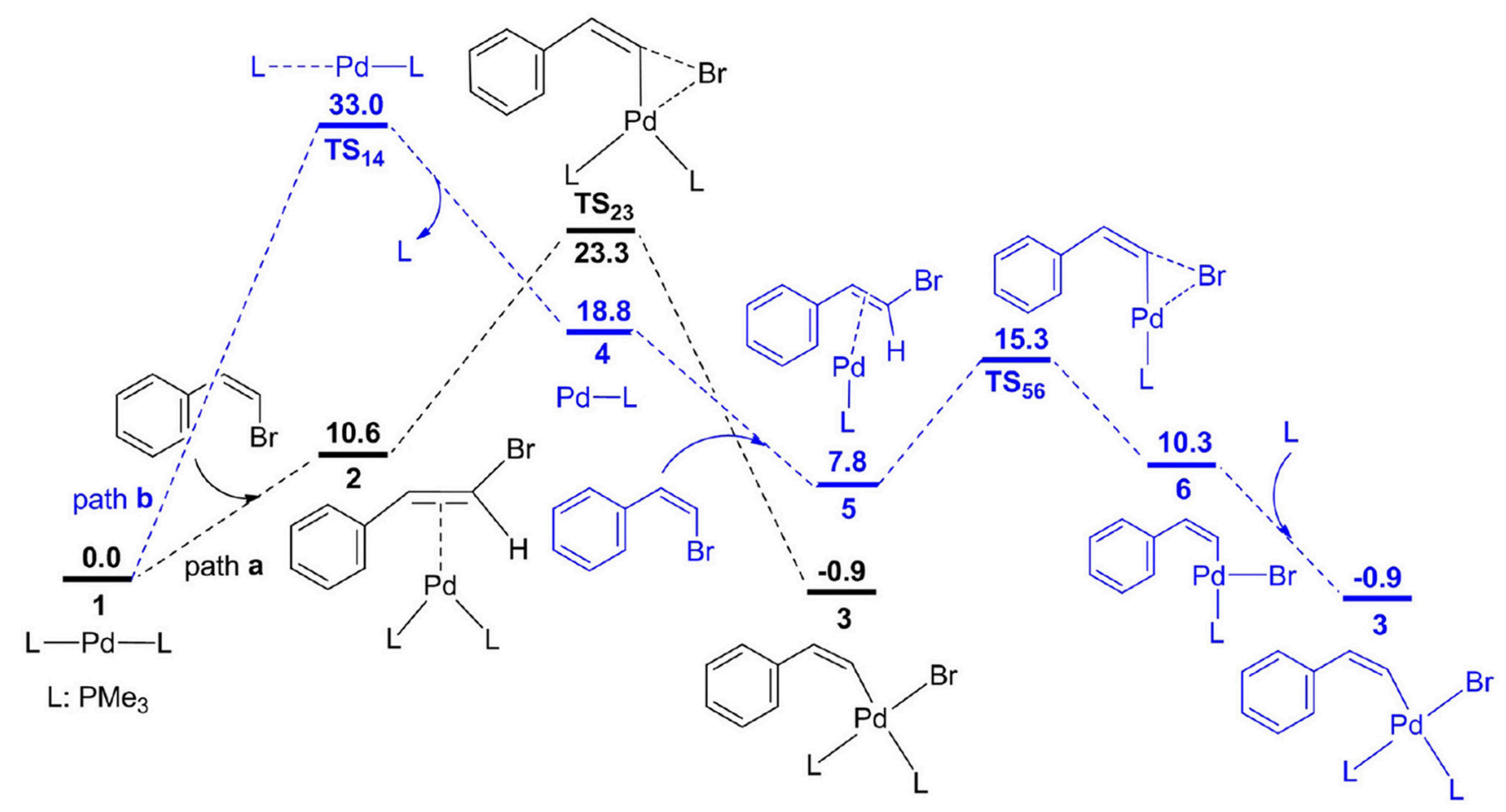

FIGURE 1 | Free energy profiles for two possible oxidative addition pathways.

reduce the costs for computation, the triphenylphosphine $\left(\mathrm{PPh}_{3}\right)$ ligand used in experiments was replaced by trimethylphosphine $\left(\mathrm{PMe}_{3}\right)$, and the reliability of this models has been validated by previous calculations (Xie et al., 2013a,b). All calculations were performed by Gaussian09 software (Frisch et al., 2009).

A continuum medium strategy based on the optimized species in gas-phase was performed to obtain single point energy in solvent. We selected the conductorlike polarizable continuum model (CPCM) involving an UAHF radii method (Barone and Cossi, 1998; Cossi et al., 2003). Toluene was utilized as solvent based on reaction conditions.

The entropy change was taken into consideration in a bimolecular process, and the corrections were added to the free energies based on the free volume theory (Benson, 1982). For 2 to 1 (or 1 to 2 ) change, a correction of -2.6 (or 2.6) $\mathrm{kcal} / \mathrm{mol}$ was necessary. The corrections have been validated by previous calculations (Okuno, 1997; Ardura et al., 2005; Liu et al., 2009, 2012; Schoenebeck and Houk, 2010; Wang et al., 2012a,b). The relative Gibbs free energies from solvent were adopted to analyze the reaction mechanisms in this manuscript.

\section{RESULTS AND DISCUSSION}

Oxidative addition is expected to be the initial step for Pdcatalyzed methylcyclopropanation of norbornene with vinyl bromide, and the corresponding free energy profiles are shown in Figure 1, and optimized geometries for different transition states are described in Figure 2. From palladium bisphosphine complex $\mathbf{1}$, two possible pathways for the formation of complex 3 are proposed. Path a (black) is related to the bisphosphine pathway and path $\mathbf{b}$ (blue) involves the monodentate phosphine pathway. The calculation results showed that path $\mathbf{a}$ is preferred. In path $\mathbf{a}$, the double bond of substrate (Z)-2-bromovinylbenzene is coordinated to the Pd center to produce complex 2 , and the process is endergonic via $10.6 \mathrm{kcal} / \mathrm{mol}$. Subsequently, the three-membered ring oxidative addition transition state has been located with an overall barrier of $23.3 \mathrm{kcal} / \mathrm{mol}$ from $\mathbf{1}$ to $\mathrm{TS}_{23}$, and generates a square-planar complex $\mathbf{3}$. In path $\mathbf{b}$, one phosphine ligand of complex $\mathbf{1}$ is dissociated to give complex $\mathbf{4}$, and the barrier is predicted to be $33.0 \mathrm{kcal} / \mathrm{mol}$ for dissociation process based on the method proposed by Hall and coworkers (Hartwig et al., 2005). From 4, the substrate enters into reaction system to yield complex 5, followed by oxidative addition with a barrier $\left(\mathrm{TS}_{56}\right)$ of $7.5 \mathrm{kcal} / \mathrm{mol}$ to afford a three-coordinate complex 6. Finally, complex $\mathbf{3}$ is produced via the coordination of phosphine ligand.

From 3, the reaction proceeds by intermolecular alkene insertion step, and two possible pathways are presented considering different coordination directions of endo- $\mathrm{N}$ (p-tolyl)-norbornenesuccinimide (Figure 3). In path c, two bridge-hydrogen atoms and the bridge-carbon atom of norbornene moieties are outside of the plane. While in path d, two bridge-hydrogen atoms and the bridge-carbon 


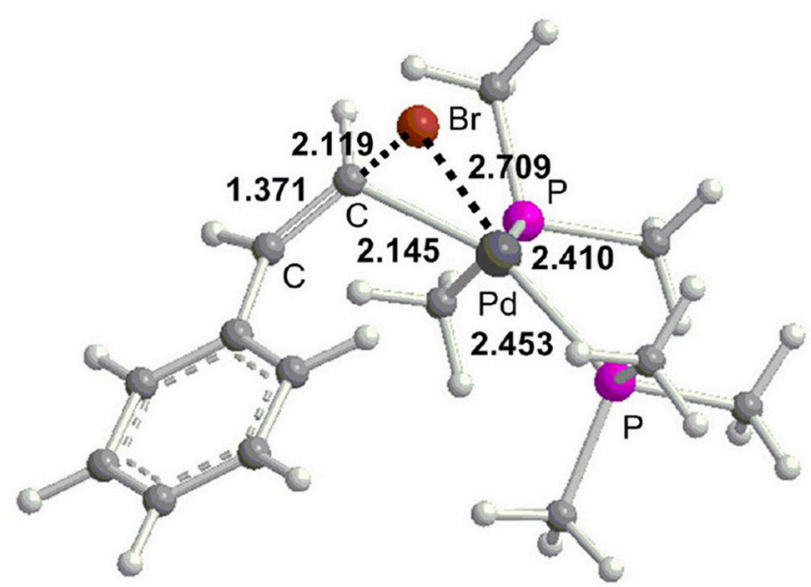

$\mathrm{TS}_{23}$

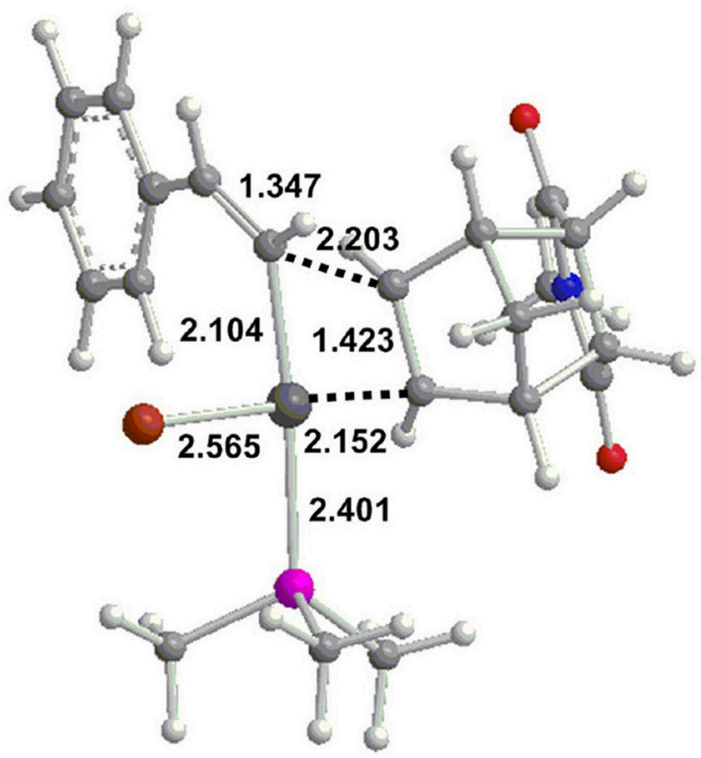

$\mathrm{TS}_{78}$

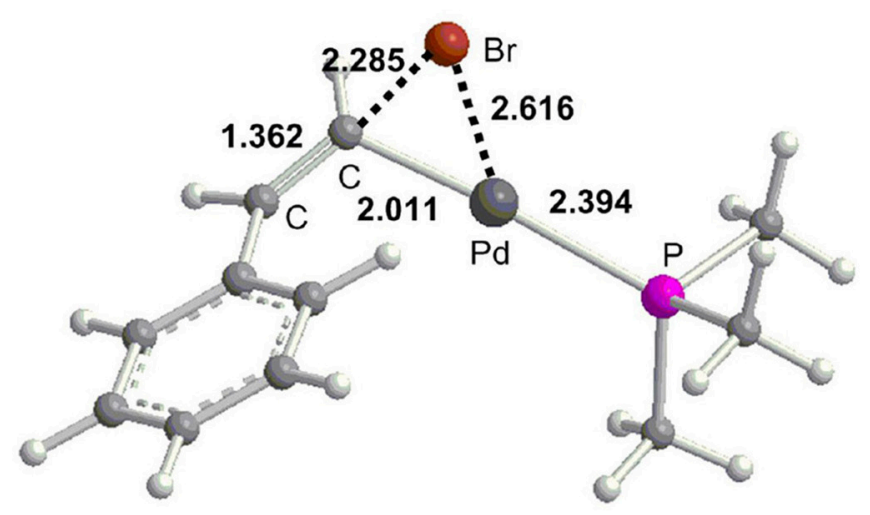

$\mathrm{TS}_{56}$

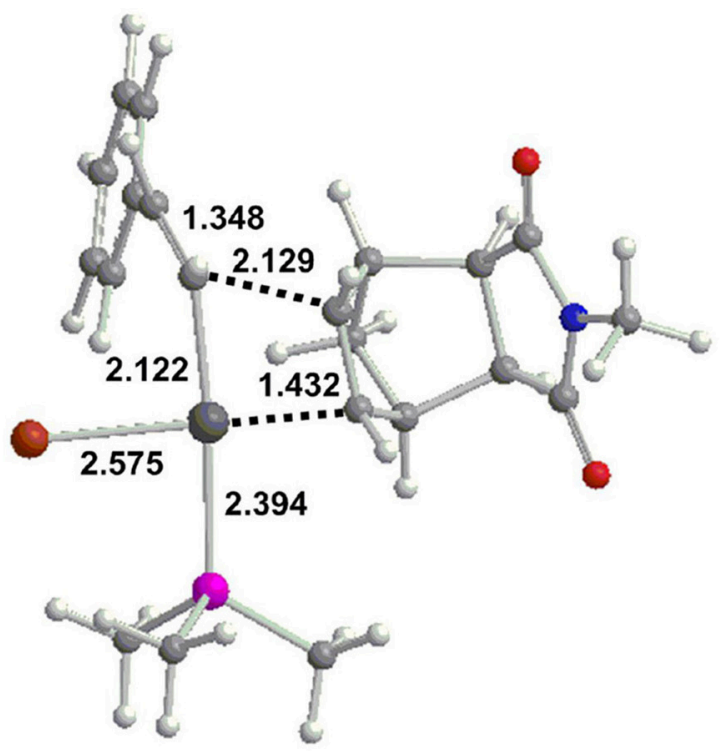

$\mathrm{TS}_{78}$

FIGURE 2 | Optimized geometries $(\AA ̊)$ for selected transition states.

atom of norbornene moieties locate inside of the plane. According to the calculations, path $\mathrm{c}\left(12.2 \mathrm{kcal} / \mathrm{mol}\right.$ for $\left.\mathrm{TS}_{78}\right)$ is more favorable than path $\mathbf{d}\left(17.3 \mathrm{kcal} / \mathrm{mol}\right.$ for $\left.\mathbf{T S}_{78^{\prime}}\right)$ by $5.1 \mathrm{kcal} / \mathrm{mol}$, then a stable four-coordinate intermediate $\mathbf{8}$ is formed and this process is obviously exergonic by $17.7 \mathrm{kcal} / \mathrm{mol}$.

From 8, we consider the possibility for the formation of ion pair complex 9' as described in previous experiments (Mao et al., 2015). The calculations showed the relative Gibbs free energy of this complex is very high with a value of $68.1 \mathrm{kcal} / \mathrm{mol}$ (Figure 4), thus we exclude this possibility. Alternatively, we investigate the key role of base in deprotonation, which has been confirmed in previous experiments (Wasa et al., 2009; Liang et al., 2012) and calculations (Biswas et al., 2000; Davies et al.,
2005; Lafrance et al., 2007; Ess et al., 2008; Kefalidis et al., 2010; Figg et al., 2013; Xie et al., 2013c, 2016). However, it is interesting to note that the $\gamma-\mathrm{H}_{1}$ in complex $\mathbf{8}$ is far away from palladium center with the $\mathrm{Pd}-\mathrm{H}_{1}$ distance of $5.268 \AA$ (Figure 4), therefore, it is very difficult to activate this $\mathrm{C}-\mathrm{H}_{1}$ bond. The $\gamma-\mathrm{C}-\mathrm{H}$ activation has been previously accomplished by $\mathrm{Yu}$ et al. (Li et al., 2014; Jiang et al., 2016; Wu et al., 2016; Shao et al., 2017, 2018; Zhu et al., 2018), and they developed a weakly coordinating directing group to help the $\mathrm{C}-$ $\mathrm{H}$ bond activation. From 8, the ligand substitution of $\mathrm{Cs}_{2} \mathrm{CO}_{3}$ and $\mathrm{CsCO}_{3}^{-}$for $\mathrm{Br}^{-}$occurs to give a stable complex 9, where the $\gamma-\mathrm{H}_{1}$ generates weak hydrogen bond interaction with the oxygen atom of $\mathrm{CsCO}_{3}^{-}$. The $\gamma-\mathrm{C}-\mathrm{H}_{1}$ distance is $1.110 \AA$ in complex 9 (Figure 5), indicating that this bond has been 


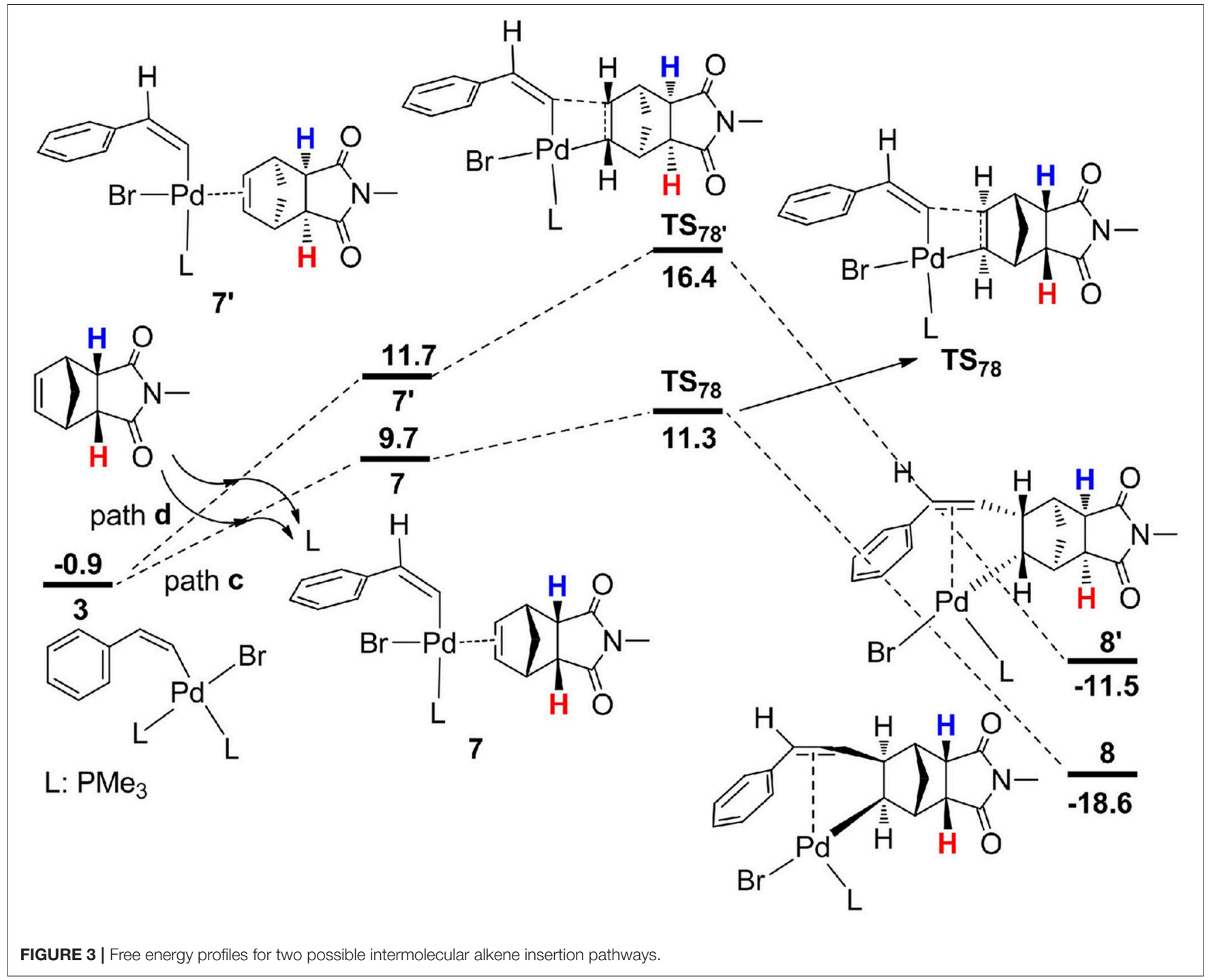

activated. Subsequently, the deprotonation is easy to take place to give complex 10 with a barrier $\left(\right.$ TS $_{9-10}$ ) of only $8.9 \mathrm{kcal} / \mathrm{mol}$. The $\mathrm{C}-\mathrm{H}_{1}$ and $\mathrm{O}-\mathrm{H}_{1}$ bond length in $\mathbf{T S}_{9-10}$ are $1.430 \AA$ and $1.221 \AA$, respectively (Figure 5). For comparison, the $\alpha$ $\mathrm{H}$ and $\beta-\mathrm{H}$ on the same side of $\mathrm{Pd}$ center can be activated by palladium center, and the barriers for $\alpha-\mathrm{H}(26.8 \mathrm{kcal} / \mathrm{mol})$ and $\beta-\mathrm{H}(14.2 \mathrm{kcal} / \mathrm{mol})$ are much higher than that of $\gamma-\mathrm{H}$. From 10, the ligand substitution of five $\mathrm{CH}_{3} \mathrm{OH}$ molecules for $\mathrm{Cs}_{2} \mathrm{CO}_{3}$ and $\mathrm{CsHCO}_{3}$ takes place to generate an unstable complex 10, and this process is significantly endergonic by $25.7 \mathrm{kcal} / \mathrm{mol}$, accompanied by protonation via $\mathrm{TS}_{11-12}$ to yield complex 12. It is worth noting that the proton comes from hydroxyl of methanol. An overall barrier of protonation step is $28.5 \mathrm{kcal} / \mathrm{mol}$ from $\mathbf{1 0}$ to $\mathbf{T S}_{11-12}$, which is the ratelimiting step of catalytic cycle. We have used several density functionals including B3LYP-D3 (Becke, 1993; Stephens et al., 1994), TPSS (Tao et al., 2003), M06-2X (Zhao and Truhlar, 2008), WB97X-D (Chai and Head-Gordon, 2008) to evaluate the functional dependency of this transition metal system. The calculations demonstrated that different functionals have slight effect on the rate-determining state. The barriers $\left(\mathbf{T S}_{11-12}\right)$ for B3LYP-D3, TPSS, M06-2X, and WB97X-D are 26.9, 31.2, 29.3 , and $27.8 \mathrm{kcal} / \mathrm{mol}$, respectively. From 12, intramolecular alkene insertion occurs to give a cyclopropanepalladium complex 13 and it requires a barrier $\left(\mathrm{TS}_{12-13}\right)$ of only $3.0 \mathrm{kcal} / \mathrm{mol}$. Then complex $\mathbf{1 4}$ is generated via the release of four methanol molecules. We know that the $\gamma-\mathrm{H}_{1}$ in complex $\mathbf{8}$ is far away from palladium center, thus five $\mathrm{CH}_{3} \mathrm{OH}$ molecules are necessary to form the hydrogen bonding network between $\gamma-\mathrm{H}_{1}$ and $\mathrm{Pd}$ center for proton transfer in $\mathbf{T S}_{11-12}$. In addition, we also considered the influence of methanol number on the barriers for proton transfer, and the calculations showed that it has only slight effect. The barriers are $28.5 \mathrm{kcal} / \mathrm{mol}\left(\mathrm{TS}_{11-12}\right)$ for five methanol molecules, $31.4 \mathrm{kcal} / \mathrm{mol}\left(\mathrm{TS}_{11-12_{-}} \mathrm{A}\right)$ for six methanol molecules, $30.9 \mathrm{kcal} / \mathrm{mol}\left(\mathrm{TS}_{11-12_{-} \mathrm{B}}\right)$ for seven methanol molecules, and $30.3 \mathrm{kcal} / \mathrm{mol}\left(\mathrm{TS}_{11-12_{-}} \mathrm{C}\right)$ for eight 


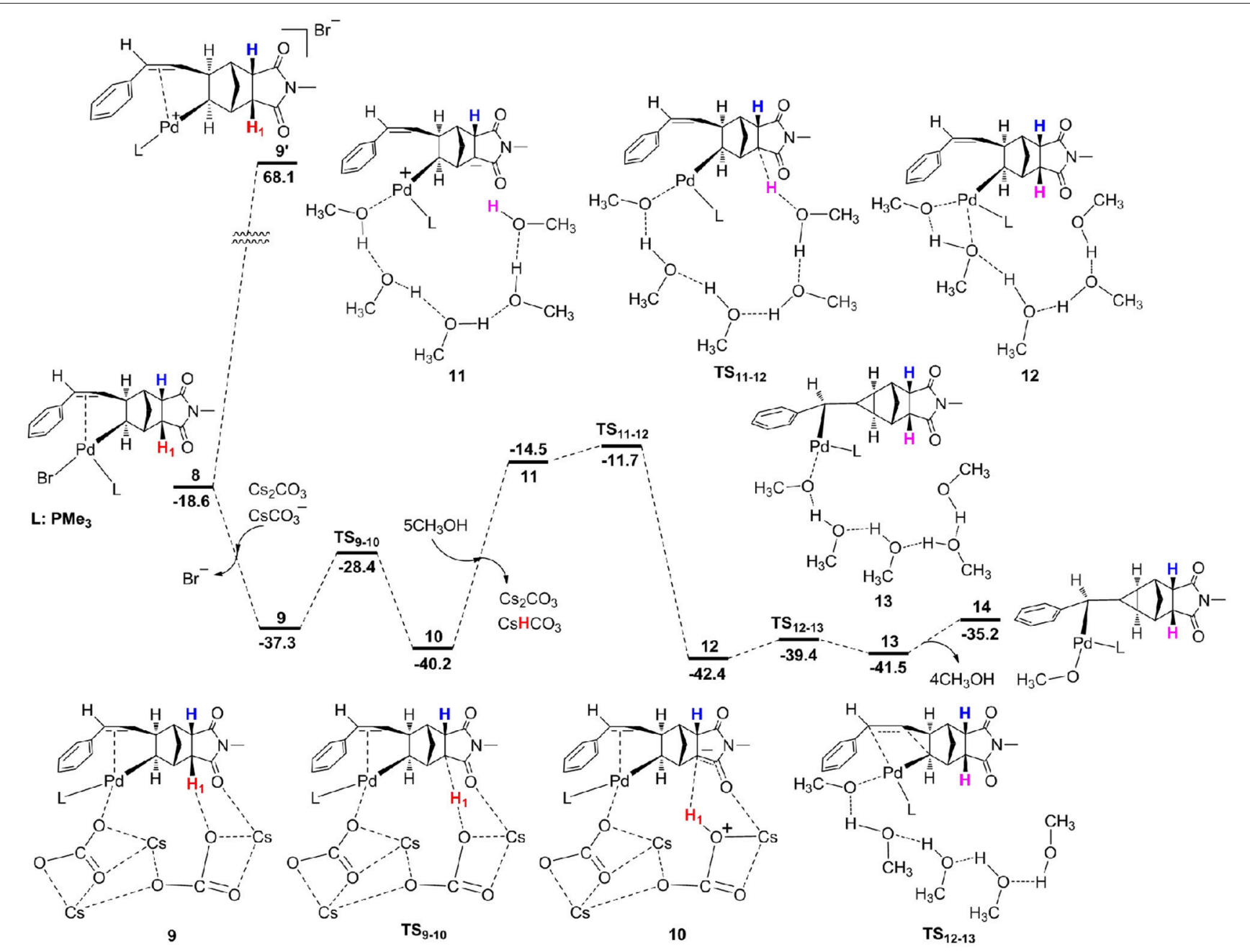

FIGURE 4 | Free energy profiles for proton exchange with $\mathrm{CH}_{3} \mathrm{OH}$ and intramolecular alkene insertion.

methanol molecules, respectively (see Supporting Information). We also consider the other possible pathway for proton exchange with $\mathrm{CH}_{3} \mathrm{OH}$ and intramolecular alkene insertion, where the intramolecular alkene insertion occurs first (see Figure S1). The calculations illustrated that the protonation by methanol molecule is the rate-determining step for catalytic cycle, and needs much higher overall barrier $\left(35.8 \mathrm{kcal} / \mathrm{mol}\right.$ from $\mathbf{1 1}^{\prime}$ to $\left.\mathrm{TS}_{12-13^{\prime}}\right)$ than the barrier mentioned above $(28.5 \mathrm{kcal} / \mathrm{mol}$ from 10 to $\mathbf{T S}_{11-12}$ ).

From 14, the reaction can proceed via $\beta-\mathrm{H}$ elimination and two possible pathways are proposed due to the existence of two $\beta-\mathrm{H}$ atom for $\mathrm{Pd}$ center (Figure 6). One is from methoxyl group (path e) and the other is from the cyclopropane carbon-bonded hydrogen atom (path f). The calculations demonstrated that path e $\left(16.7 \mathrm{kcal} / \mathrm{mol}\right.$ for $\left.\mathbf{T S}_{14-15}\right)$ is more favorable than path $\mathbf{d}\left(23.0 \mathrm{kcal} / \mathrm{mol}\right.$ for $\left.\mathbf{T S}_{14-16}\right)$, and optimized geometries of two transition states are described in Figure 7. Subsequently, a square-planar complex 15 is generated, followed by the release of methanal to produce complex 17. A methylcyclopropane product is then formed via the $\mathrm{C}-\mathrm{H}$ bond reductive elimination, and it needs a barrier $\left(\mathrm{TS}_{17-4}\right)$ of $9.5 \mathrm{kcal} / \mathrm{mol}$. Finally, one phosphine ligand is coordinated to the $\mathrm{Pd}$ center to regenerate the catalyst. It is clearly to see that the proton for the protonation of a methylcyclopropane subunit comes from the methyl of $\mathrm{CH}_{3} \mathrm{OH}$, which is consistent with the deuterium-labeling experiments (Fedorynski, 2003).

As described in Figure 8, the catalytic cycle for the reaction of (Z)-2-bromovinylbenzene with endo-N(p-tolyl)-norbornenesuccinimide undergoes six steps, consist of oxidative addition (OA), intermolecular olefin insertion, deprotonation/protonation, intramolecular olefin insertion, $\beta-\mathrm{H}$ elimination and reductive elimination (RE), and protonation is the rate-determining step and requires an overall barrier of $28.5 \mathrm{kcal} / \mathrm{mol}$ from $\mathbf{1 0}$ to $\mathrm{TS}_{11-12}$. 


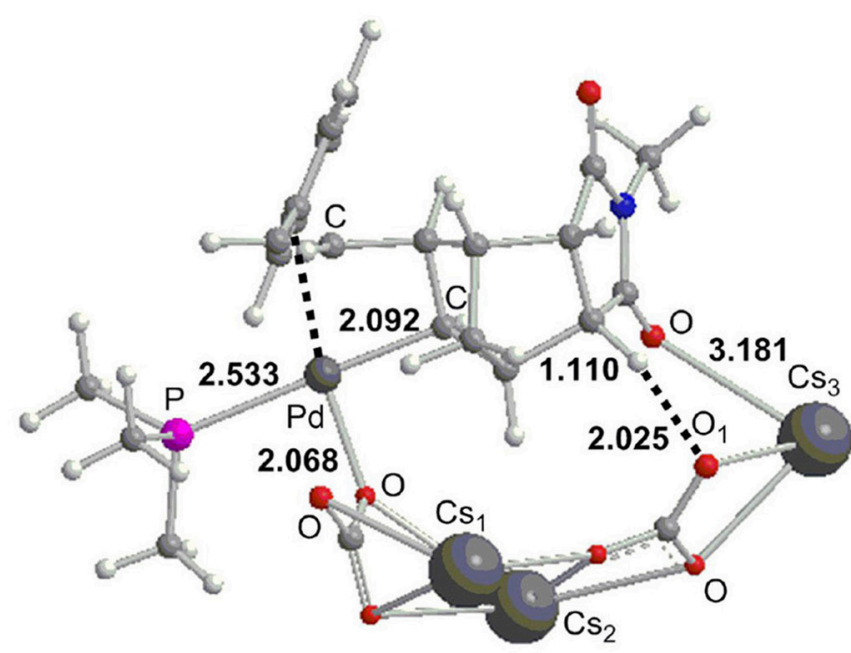

9

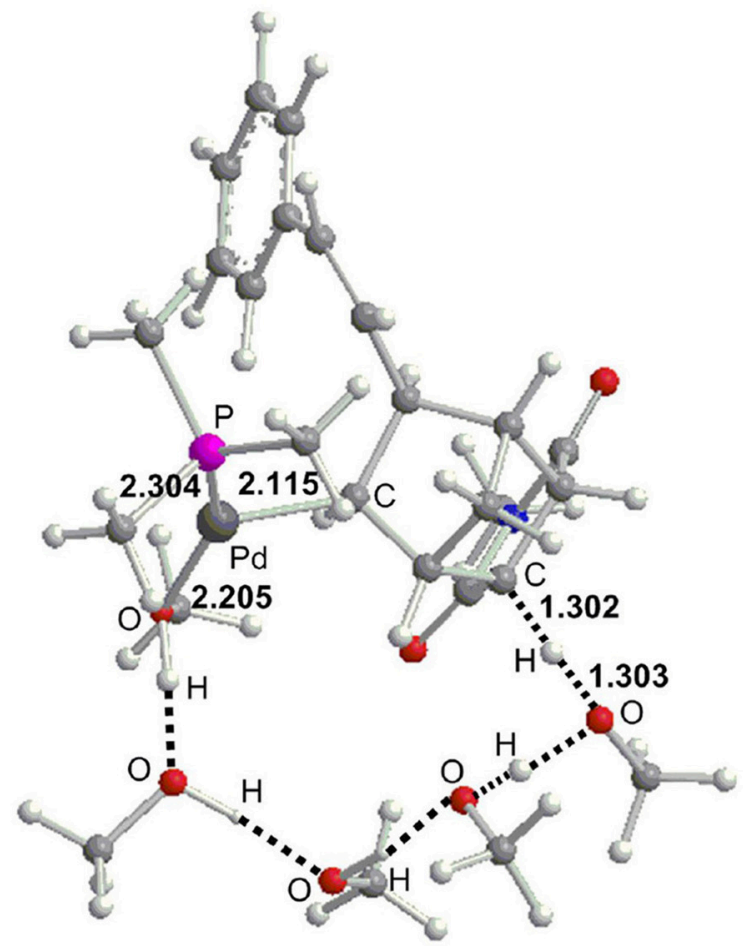

$\mathrm{TS}_{11-12}$

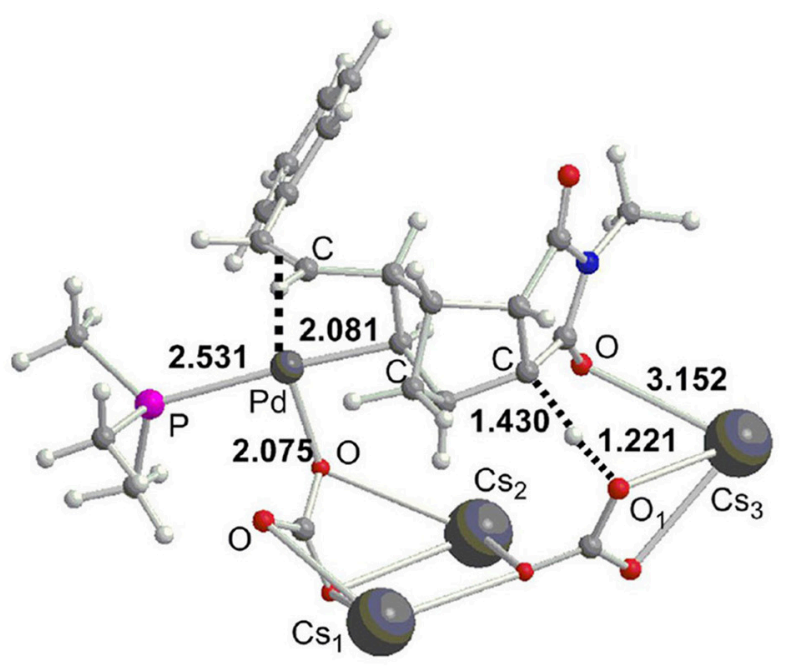

$\mathrm{TS}_{9-10}$

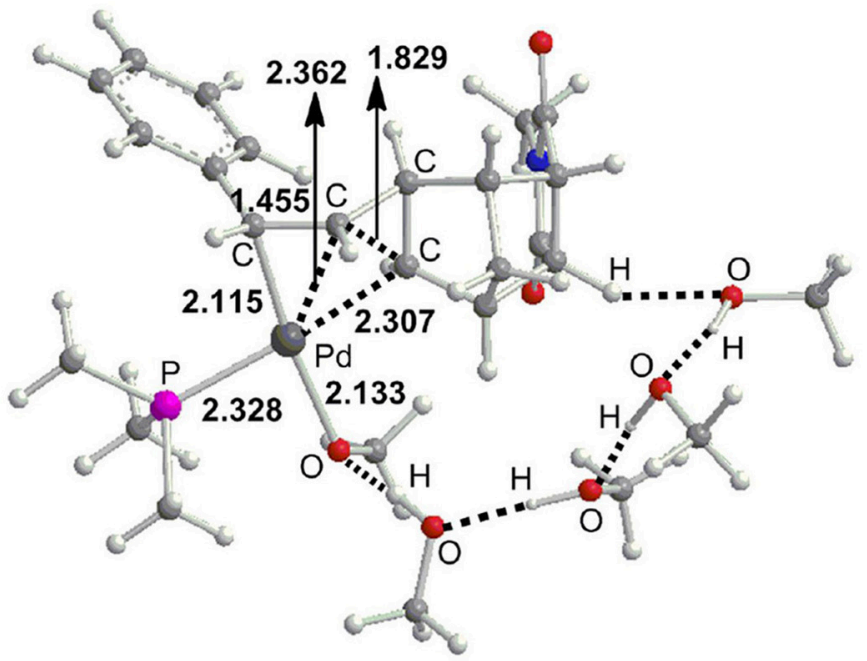

$\mathrm{TS}_{12-13}$ 


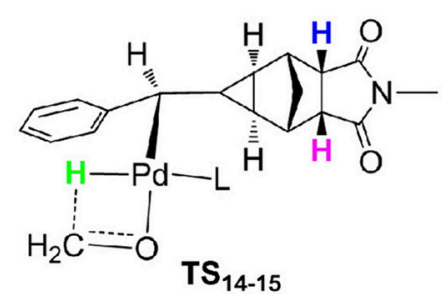

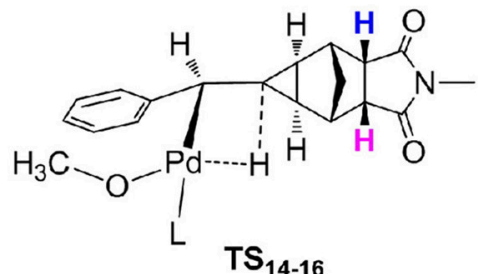

$\mathrm{TS}_{14-16}$<smiles>CO[I](I)(I)/C=C/c1ccccc1</smiles>

$\mathrm{TS}_{14-16}$

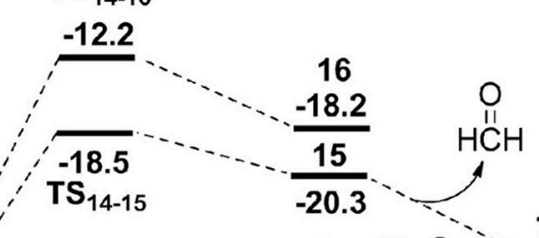

íp path e

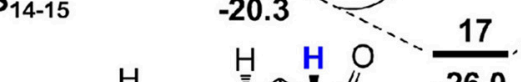

$\frac{14}{35.2}$<smiles>C/C=C\P=[Pb]</smiles>

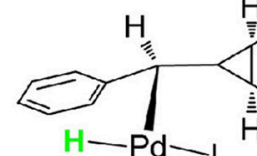

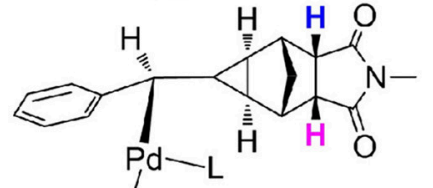
$\mathrm{H}_{2} \mathrm{C}=\mathrm{O}$

$\mathrm{H}_{3} \mathrm{C}-\mathrm{O}$

$\mathrm{L}: \mathrm{PMe}_{3}$<smiles>O=C1CCCN1C(=O)C1CCCCC1</smiles>

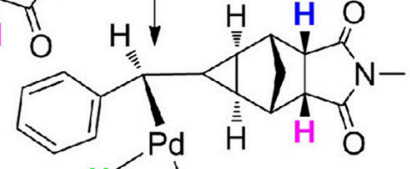

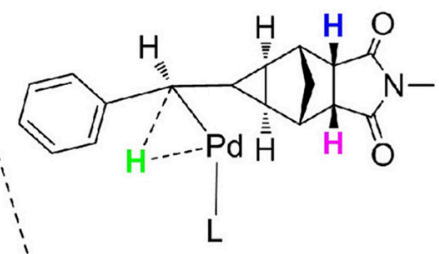

$-16.5$
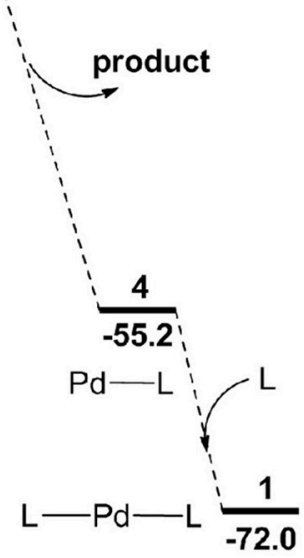

FIGURE 6 | Free energy profiles for $\beta$-H elimination and $\mathrm{C}-\mathrm{H}$ bond reductive elimination.

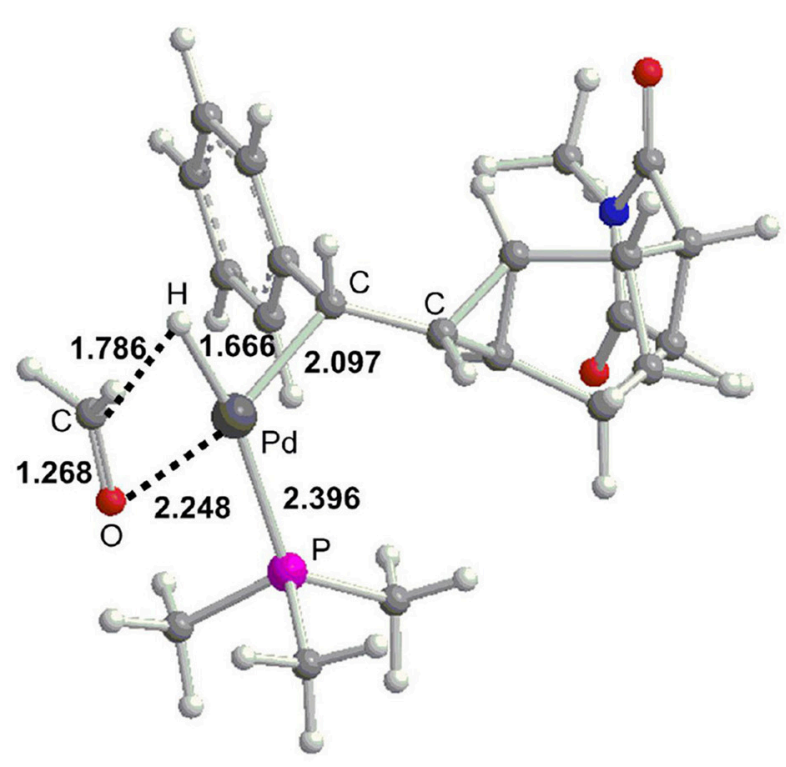

$\mathrm{TS}_{14-15}$

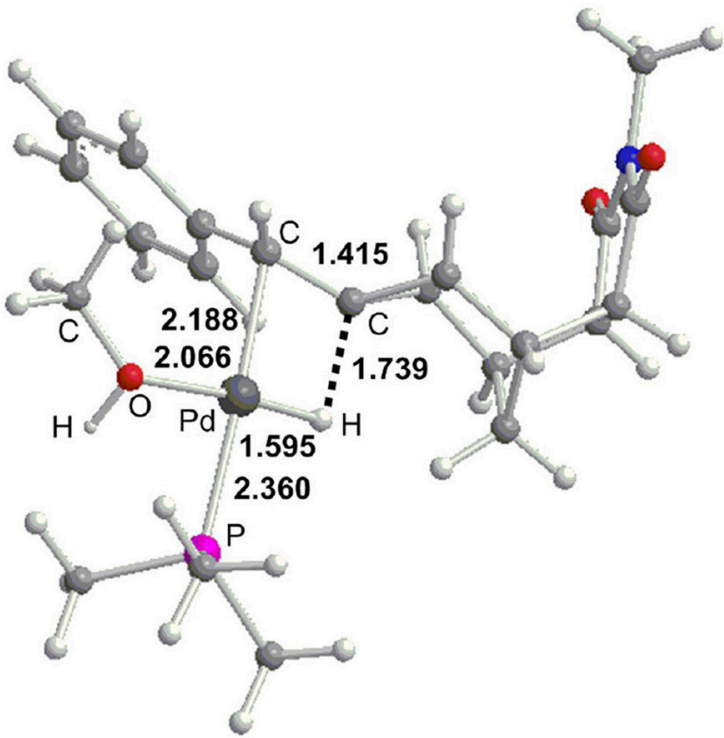

$\mathrm{TS}_{14-16}$

FIGURE 7 | Optimized geometries ( $(\AA)$ for selected transition states as presented in Figure 6. 


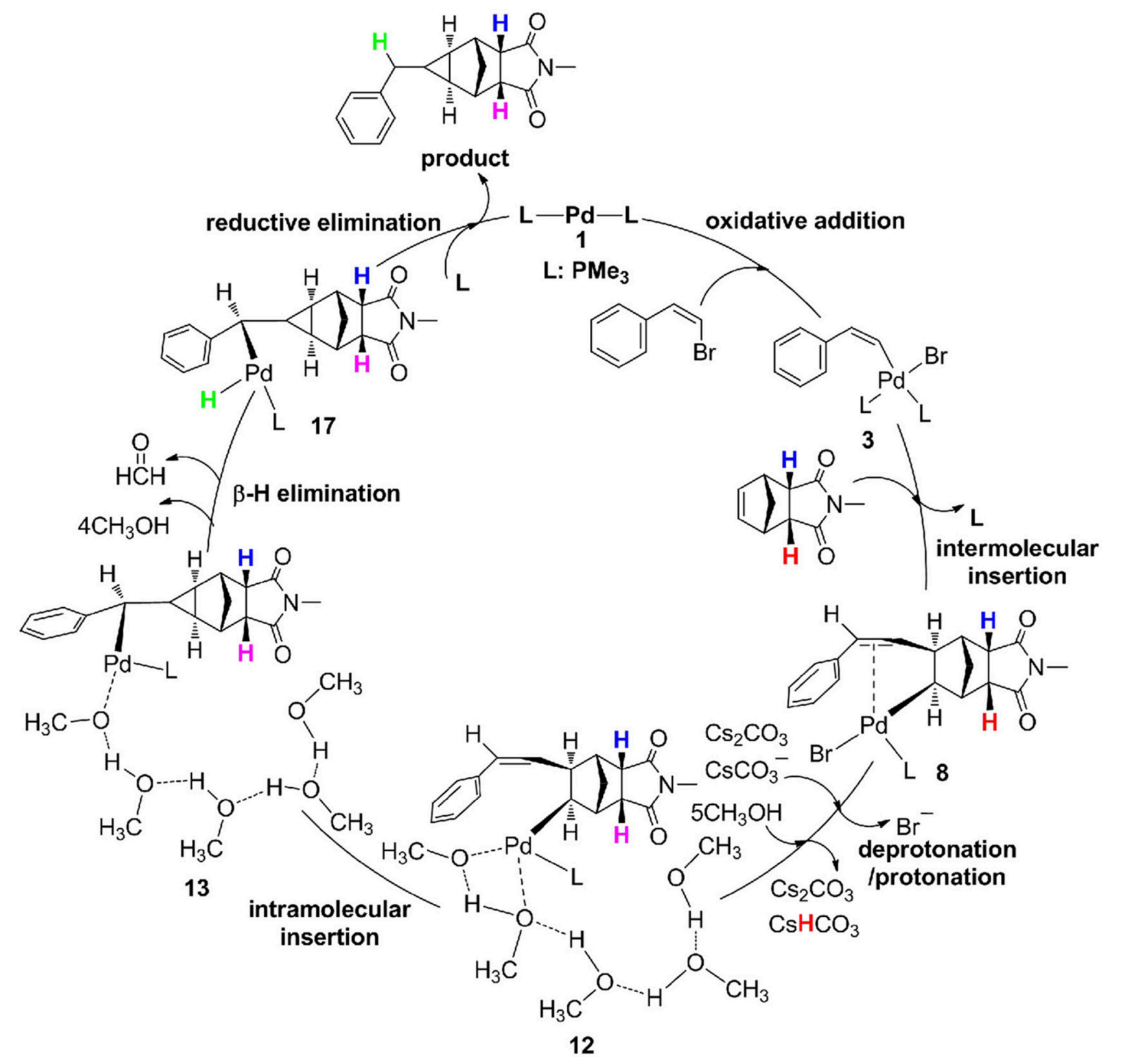

FIGURE 8 | Catalytic cycle for palladium-catalyzed methylcyclopropanation between (Z)-2-bromovinylbenzene and endo-N-(p-tolyl)-norbornenesuccinimide.

\section{CONCLUSIONS}

In conclusion, Pd-catalyzed $[2+1]$ cycloaddition domino reaction mechanisms of (Z)-2-bromovinylbenzene and endo-N-(p-tolyl)-norbornenesuccinimide have been studied by DFT calculations. The results revealed that the methylcyclopropanation process underwent six steps, including oxidative addition, intermolecular alkene insertion, deprotonation/protonation, intramolecular alkene insertion, $\beta-\mathrm{H}$ elimination and reductive elimination, and protonation by methanol is the rate-limiting step with an overall barrier of 28.5 $\mathrm{kcal} / \mathrm{mol}$. In addition, the hydrogen atoms for protonation and exchange are both from the methanol, and the former comes from the methyl of methanol, and the latter comes from the hydroxyl of methanol. These calculation results are consistent with the deuterium-labeling experiments.

\section{AUTHOR CONTRIBUTIONS}

The work was completed by cooperation of all authors. HX and WB were responsible for the study of concept and design of the project. FY, YZ, CX, and ZS searched the intermediates and transition states and analyzed the data and drew energy profiles. FY, YZ, HX, and WB drafted and revised the manuscript. 


\section{FUNDING}

This work was supported by the National Natural Science Foundation of China (21203166), the Natural Science Foundation of Zhejiang Province (LY17B050001).

\section{REFERENCES}

Amatore, C., Jutand, A., and M'Barki, M., A. (1992). Evidence of the formation of zerovalent palladium from $\mathrm{Pd}(\mathrm{OAc})_{2}$ and triphenylphosphine. Organometallics 11, 3009-3013. doi: 10.1021/om00045a012

Ardura, D., López, R., and , Sordo, T. L. (2005). Relative gibbs energies in solution through continuum models: effect of the loss of translational degrees of freedom in bimolecular reactions on gibbs energy barriers. J. Phys. Chem. B 109, 23618-23623. doi: 10.1021/jp0540499

Barone, V., and Cossi, M. (1998). Quantum calculation of molecular energies and energy gradients in solution by a conductor solvent model. J. Phys. Chem. A 102, 1995-2001. doi: 10.1021/jp9716997

Beaulieu, L. P., Schneider, J. F., and Charette, A. B. (2013). Highly enantioselective simmons-smith fluorocyclopropanation of allylic alcohols via the halogen ccrambling strategy of zinc carbenoids. J. Am. Chem. Soc. 135, 7819-7822. doi: $10.1021 / \mathrm{ja} 402393 \mathrm{w}$

Becke, A. D. (1993). Density-functional thermochemistry. III. the role of exact exchange. J. Chem. Phys. 98, 5648-5652. doi: 10.1063/1.464913

Benson, S. W. (1982). The Foundations of Chemical Kinetics. Malabar, FL: Krieger.

Bigeault, J., Giordano, L., and Buono, G. (2005). [2+1] Cycloadditions of terminal alkynes to norbornene derivatives catalyzed by palladium complexes with phosphinous acid ligands. Angew. Chem. Int. Ed. 44, 4753-4757. doi: 10.1002/anie.200500879

Biswas, A., De Sarkar, S., Tebben, L., and Studer, A. (2012). Enantioselective cyclopropanation of enals by oxidative N-heterocyclic carbene catalysis. Chem. Coтmu. 48, 5190-5192. doi: 10.1039/c2cc31501g

Biswas, B., Sugimoto, M., and Sakaki, S. (2000). C-H bond activation of benzene and methane by $\mathrm{M}\left(\eta^{2}-\mathrm{O}_{2} \mathrm{CH}\right)_{2}(\mathrm{M}=\mathrm{Pd}$ or $\mathrm{Pt})$. a theoretical study. Organometallics 19, 3895-3908. doi: 10.1021/om000002s

Bruneau, C. (2005). Electrophilic activation and cycloisomerization of enynes: a new route to functional cyclopropanes. Angew. Chem., Int. Ed 44, 2328-2334. doi: 10.1002 /anie.200462568

Chai, J. D., and Head-Gordon, M. (2008). Systematic optimization of longrange corrected hybrid density functionals. J. Chem. Phys. 128:084106. doi: $10.1063 / 1.2834918$

Check, C. E., Faust, T. O., Bailey, J. M., Wright, B. J., Gilbert, T. M., and Sunderlin, L. S. (2001). Addition of polarization and diffuse functions to the LANL2DZ basis set for P-block elements. J. Phys. Chem. A 105, 8111-8116. doi: $10.1021 /$ jp011945l

Chen, J., Levant, B., Jiang, C., Keck, T. M., Newman, A. H., and Wang, S. (2014). Tranylcypromine substituted cis-hydroxycyclobutylnaphthamides as potent and selective dopamine $\mathrm{D}_{3}$ receptor antagonists. J. Med. Chem. 57, 4962-4968. doi: 10.1021/jm401798r

Cossi, M., Rega, N., Scalmani, G., and Barone, V. (2003). Energies, structures, and electronic properties of molecules in solution with the C-PCM solvation model. J. Comput. Chem. 24, 669-681. doi: 10.1002/jcc. 10189

Crowley, M. P., Inglis, H. S., Snarey, M., and Thain, E. M. (1961). Biosynthesis of the pyrethrins. Nature 191, 281-282. doi: 10.1038/191281a0

Dash, P., and Janni, M. S. (2012). Perunchera-lathan, trideuteriomethoxylation of aryl and heteroaryl halides. Eur. J. Org. Chem. 2012, 4914-4917. doi: 10.1002/ejoc.201200753

Davies, D. L., Donald, M. A., and Macgregor, S. A. (2005). Computational study of the mechanism of cyclometalation by palladium acetate. J. Am. Chem. Soc. 127, 13754-13755. doi: $10.1021 / \mathrm{ja} 052047 \mathrm{w}$

de Meijere, A. (2003). Introduction: cyclopropanes and related rings. Chem. Rev. 103, 931-932. doi: $10.1021 / \mathrm{cr} 0100289$

\section{SUPPLEMENTARY MATERIAL}

The Supplementary Material for this article can be found online at: https://www.frontiersin.org/articles/10.3389/fchem. 2019.00169/full\#supplementary-material

Du, W., Gu, Q., Li, Z., and Yang, D. (2015). Palladium(II)-catalyzed intramolecular tandem aminoalkylation via divergent $\mathrm{C}\left(\mathrm{sp}_{3}\right)-\mathrm{H}$ functionalization. J. Am. Chem. Soc. 137, 1130-1135. doi: 10.1021/ja5102739

Ehlers, A. W., Bohme, M., Dapprich, S., Gobbi, A., Hollwarth, A., Jonas, V., et al. (1993). A set of f-polarization functions for pseudo-potential basis sets of the transition metals Sc-Cu, Y-Ag and La-Au. Chem. Phys. Lett. 208, 111-114. doi: 10.1016/0009-2614(93)80086-5

Ess, D. H., Bischof, S. M., Oxgaard, J., Periana, R. A., and Goddard, W. A. (2008). Transition state energy decomposition study of acetate-assisted and internal electrophilic substitution $\mathrm{C}-\mathrm{H}$ bond activation by (acac- $\mathrm{O}, \mathrm{O})_{2} \operatorname{Ir}(\mathrm{X})$ complexes $\left(\mathrm{X}=\mathrm{CH}_{3} \mathrm{COO}, \mathrm{OH}\right)$. Organometallics 27, 6440-6445. doi: 10.1021/om8006568

Fedorynski, M. (2003). Syntheses of gem-dihalocyclopropanes and their use in organic synthesis. Chem. Rev. 103, 1099-1132. doi: 10.1021/cr0100087

Figg, T. M., Wasa, M., Yu, J. Q., and Musaev, D. G. (2013). Understanding the reactivity of $\mathrm{Pd}(0) / \mathrm{PR}_{3}$-catalyzed intermolecular $\mathrm{C}\left(\mathrm{sp}^{3}\right)-\mathrm{H}$ bond arylation. $J$. Am. Chem. Soc. 135, 14206-14214. doi: 10.1021/ja4053416

Frisch, M. J., Trucks, G. W., Schlegel, H. B., Scuseria, G. E., Robb, M. A., Cheeseman, J. R., et al. (2009). Gaussian 09, Revision A.1. Wallingford CT: Gaussian, Inc.

Fukui, K. (1970). Formulation of the reaction coordinate. J. Phys. Chem. 74, 4161-4163. doi: 10.1021/j100717a029

Fukui, K. (1981). The path of chemical reactions-the IRC approach. Acc. Chem. Res. 14, 363-368. doi: 10.1021/ar00072a001

Goudreau, S. R., and Charette, A. B. (2010). Defying ring strain: new approaches to cyclopropanes. Angew. Chem. Int. Ed. 49, 486-488. doi: 10.1002/anie.200905109

Hartwig, J. F., Cook, K. S., Hapke, M., Incarvito, C. D., Fan, Y. B. Webster, C. D., et al. (2005). Rhodium boryl complexes in the catalytic, terminal functionalization of alkanes. J. Am. Chem. Soc. 127, 2538-2552. doi: $10.1021 /$ ja045090c

Hata, Y., Zimmermann, S., Quitschau, M., Kaiser, M., Hamburger, M., and Adams, M. (2011). Antiplasmodial and antitrypanosomal activity of pyrethrins and pyrethroids. J. Agric. Food Chem. 59, 9172-9176. doi: 10.1021/jf20 $1776 \mathrm{z}$

Hiratsuka, T., Suzuki, H., Kariya, R., Seo, T., Minami, A., and Oikawa, H. (2014). Enantioselective synthesis of $\alpha$-alkylidene- $\gamma$-butyrolactones: intramolecular rauhut-currier reaction promoted by acid/base organocatalysts. Angew. Chem. Int. Ed. 53, 5423-5426. doi: 10.1002/anie.201402623

Hofmann, K., Jucker, O., Miller, W. R., Young, A. C., and Tausig, F. (1954). On the structure of lactobacillic acid. J. Am. Chem. Soc. 76, 1799-1804. doi: $10.1021 /$ ja01636a020

Huzinaga, S. (1984). Gaussian Basis Sets for Molecular Calculations; Elsevier Science. Amsterdam: Pub. Co.

Jiang, H., He, J., Liu, T., and Yu, J. Q. (2016). Ligand-enabled $\gamma$-C( $\left.\mathrm{sp}^{3}\right)-$ $\mathrm{H}$ olefination of amines: en route to pyrrolidines. J. Am. Chem. Soc. 138, 2055-2059. doi: 10.1021/jacs.5b13462

Kefalidis, C. E., Baudoin, O., and Clot, E. (2010). DFT study of the mechanism of benzocyclobutene formation by palladium-catalysed $\mathrm{C}\left(\mathrm{sp}^{3}\right)-\mathrm{H}$ activation: role of the nature of the base and the phosphine. Dalton Trans. 39, 10528-10535. doi: $10.1039 / \mathrm{c0dt00578a}$

Kuwabe, S. I., Torraca, K. E., and Buchwald, S. L. (2001). Palladium-catalyzed intramolecular C-O bond formation. J. Am. Chem. Soc. 123, 12202-12206. doi: $10.1021 /$ ja012046d

Lafrance, M., Gorelsky, S. I., and Fagnou, K. (2007). High-yielding palladium-catalyzed intramolecular alkane arylation: reaction development and mechanistic studies. J. Am. Chem. Soc. 129, 14570-14571. doi: $10.1021 / \mathrm{ja} 076588 \mathrm{~s}$ 
Lebel, H., Marcoux, J. F., Molinaro, C., and Charette, A. B. (2003). Stereoselective cyclopropanation reactions. Chem. Rev. 103, 977-1050. doi: 10.1021/cr0 $10007 \mathrm{e}$

Li, S. H., Chen, G., Feng, C. G., Gong, W., and Yu, J. Q. (2014). Ligand-enabled $\gamma$-C-H olefination and carbonylation: construction of $\beta$-quaternary carbon centers. J. Am. Chem. Soc. 136, 5267-5270. doi: 10.1021/ja501689j

Liang, Y., Geng, W. Z., Wei, J. N., Ouyang, K. B., and Xi, Z. F. (2012). Palladiumcatalyzed silyl C( $\left.\mathrm{sp}^{3}\right)-\mathrm{H}$ bond activation. Org. Biomol. Chem. 10, 1537-1542. doi: 10.1039/c2ob06941e

Lindsay, V. N., Fiset, D., Gritsch, P. J., Azzi, S., and Charette, A. B. (2013). Stereoselective $\mathrm{Rh}_{2}\left(\mathrm{~S}\right.$-IBAZ) ${ }_{4}$-catalyzed cyclopropanation of alkenes, alkynes, and allenes: asymmetric synthesis of diacceptor cyclopropylphosphonates and alkylidenecyclopropanes. J. Am. Chem. Soc. 135, 1463-1470. doi: $10.1021 /$ ja3099728

Liu, B. W., Gao, M., Dang, L., Zhao, H. T., Marder, T. B., and Lin, Z. Y. (2012). DFT studies on the mechanisms of the platinum-catalyzed diboration of acyclic $\alpha, \beta$-unsaturated carbonyl compounds. Organometallics $31,3410-3425$. doi: $10.1021 / \mathrm{om} 3002153$

Liu, Q., Lan, Y., Liu, J., Li, G., Wu, Y. D., and Lei, A. (2009). Revealing a second transmetalation step in the Negishi coupling and its competition with reductive elimination: improvement in the interpretation of the mechanism of biaryl syntheses. J. Am. Chem. Soc. 131, 10201-10210. doi: 10.1021/ja9 $03277 \mathrm{~d}$

Mao, J., and Bao, W. L. (2014a). Palladium(0)-catalyzed methylenecyclopropanation of norbornenes with vinyl bromides. Org. Lett. 16, 2646-2649. doi: 10.1021/ol500829t

Mao, J., and Bao, W. L. (2014b). Palladium-catalyzed $[2+1+1]$ annulation of norbornenes with $(z)$-bromostyrenes: synthesis of bismethylenecyclobutanes via twofold $\mathrm{C}\left(\mathrm{sp}^{2}\right)-\mathrm{H}$ bond activation. Chem. Commun. 50, 15726-15729. doi: 10.1039/C4CC06545J

Mao, J., Xie, H. J., and Bao, W. L. (2015). Palladium(0)-catalyzed methylcyclopropanation of norbornenes with vinyl bromides and mechanism study. Org. Lett. 17, 3678-3681. doi: 10.1021/acs.orglett.5b01603

Mao, J. G., Zhang, S. Q., Shi, B. F., and Bao, W. L. (2014). Palladium(0)-catalyzed cyclopropanation of benzyl bromides via $\mathrm{C}\left(\mathrm{sp}^{3}\right)-\mathrm{H}$ bond activation. Chem. Commun. 50, 3692-3694. doi: 10.1039/C3CC49231A

Masutomi, K., Oguchi, K., and Tanaka, K. (2014). Enantioselective cycloisomerization of 1,6-enynes to bicyclo[3.1.0]hexanes catalyzed by rhodium and benzoic acid. J. Am. Chem. Soc. 136, 7627-7630. doi: $10.1021 /$ ja 504048 u

Matsukawa, Y., Mizukado, J., Quan, H., Tamura, M., and Sekiya, A. (2005). Palladium(0)-catalyzed hydroalkoxylation of hexafluoropropene: synthesis of hydrofluoroethers under neutral conditions. Angew. Chem. Int. Ed. 44, 1128-1130. doi: 10.1002/anie.200462200

Miege, F., Meyer, C., and Cossy, J. (2011). Rhodium-catalyzed cycloisomerization involving cyclopropenes: efficient stereoselective synthesis of mediumsized heterocyclic scaffolds. Angew. Chem. Int. Ed. 50, 5932-5937. doi: 10.1002/anie.201101220

Miki, K., Nishino, F., Ohe, K., and Uemura, S. (2002). Novel approach for catalytic cyclopropanation of akenes via (2-furyl)carbene complexes from 1-benzoyl-cis1-buten-3-yne. J. Am. Chem. Soc. 124, 5260-5261. doi: 10.1021/ja025776+

Miura, T., Sasaki, T., Harumashi, T., and Murakami, M. (2006). Vinylcyclopropanation of olefins via 3-methoxy-1-propenylrhodium(I). J. Am. Chem. Soc. 128, 2516-2517. doi: 10.1021/ja0575326

Okuno, Y. (1997). Theoretical investigation of the mechanism of the baeyer-villiger reaction in nonpolar solvents. Chem. Eur. J. 3, 212-218. doi: $10.1002 /$ chem. 19970030208

Oonishi, Y., Kitano, Y., and Sato, Y. (2012). Palladium-catalyzed asymmetric synthesis of silicon-stereogenic dibenzosiloles via enantioselective C$\mathrm{H}$ bond functionalization. Angew. Chem. Int. Ed. 51, 7305-7308. doi: 10.1002/anie.201203772

Palucki, M., Wolfe, J. P., and Buchwald, S. L. (1997). Palladium-catalyzed intermolecular carbon-oxygen bond formation: a new synthesis of aryl ethers. J. Am. Chem. Soc. 119, 3395-3396. doi: 10.1021/ja9640152

Pietruszka, J. (2003). Synthesis and properties of oligocyclopropyl-containing natural products and model compounds. Chem. Rev 103, 1051-1070. doi: $10.1021 / \mathrm{cr} 010027 \mathrm{~g}$
Reed, A. E., Curtiss, L. A., and Weinhold, F. (1988). Intermolecular interactions from a natural bond orbital, donor-acceptor viewpoint. Chem. Rev. 88, 899-926. doi: 10.1021/cr00088a005

Reed, A. E., and Weinhold, F. (1985). Natural localized molecular orbitals. J. Chem. Phys. 83, 1736-1740. doi: 10.1063/1.449360

Reed, A. E., Weinstock, R. B., and Weinhold, F. (1985). Natural population analysis. J. Chem. Phys. 83, 735-746. doi: 10.1063/1.449486

Reissig, H. U., and Zimmer, R. (2003). Donor-acceptor-substituted cyclopropane derivatives and their application in organic synthesis. Chem. Rev. 103, 1151-1196. doi: 10.1021/cr01 0016n

Satake, A., and Nakata, T. (1998). Novel $\eta^{3}$-allylpalladium-pyridinylpyrazole complex: synthesis, reactivity, and catalytic activity for cyclopropanation of ketene silyl acetal with allylic acetates. J. Am. Chem. Soc. 120, 10391-10396. doi: $10.1021 /$ ja 982269 c

Schoenebeck, F., and Houk, K. N. (2010). Ligand-controlled regioselectivity in palladium-catalyzed cross coupling reactions. J. Am. Chem. Soc. 132, 2496-2497. doi: 10.1021/ja9077528

Shao, Q., He, J., Wu, Q. F., and Yu, J. Q. (2017). Ligand-enabled $\gamma$-C(sp $\left.{ }^{3}\right)-H$ crosscoupling of nosyl-protected amines with aryl- and alkylboron reagents. ACS Catal. 7, 7777-7782. doi: 10.1021/acscatal.7b02721

Shao, Q., Wu, Q. F., He, J., and Yu, J. Q. (2018). Enantioselective $\gamma$-C $\left(\mathrm{sp}^{3}\right)-\mathrm{H}$ activation of alkyl amines via $\mathrm{Pd}(\mathrm{II}) / \mathrm{Pd}(0)$ catalysis. J. Am. Chem. Soc. 140, 5322-5325. doi: 10.1021/jacs.8b01094

Simmons, H. E., and Smith, R. D. (1958). A new synthesis of cyclopropanes from oledins. J. Am. Chem. Soc. 80, 5323-5324. doi: 10.1021/ja01552a080

Stephens, P. J., Devlin, F. J., Chabalowski, C. F., and Frisch, M. J. (1994). Ab initio calculation of vibrational absorption and circular dichroism spectra using density functional force fields. J. Phys. Chem. 98, 11623-11627. doi: 10.1021/j100096a001

Tao, J., Perdew, J. P., Staroverov, V. N., and Scuseria, G. E. (2003). Climbing the density functional ladder: nonempirical meta-generalized gradient approximation designed for molecules and solids. Phys. Rev. Lett. 91:146401. doi: 10.1103/PhysRevLett.91.146401

Torraca, K. E., Kuwabe, S. I., and Buchwald, S. L. (2000). A high-yield, general method for the catalytic frmation of oxygen heterocycles. J. Am. Chem. Soc. 122, 12907-12908. doi: 10.1021/ja005698v

Tseng, N. W., Mancuso, J., and Lautens, M. (2006). Rhodium-catalyzed tandem vinylcyclopropanation of strained alkenes. J. Am. Chem. Soc. 128, 5338-5339. doi: $10.1021 / \mathrm{ja} 060877 \mathrm{j}$

Wang, M. Y., Fan, T., and Lin, Z. Y. (2012a). DFT studies on coppercatalyzed arylation of aromatic C-H bonds. Organometallics 31, 560-569. doi: $10.1021 / \mathrm{om} 2007612$

Wang, M. Y., Fan, T., and Lin, Z. Y. (2012b). DFT studies on the reaction of $\mathrm{CO}_{2}$ with allyl-bridged dinuclear palladium(I) complexes. Polyhedron 32, 35-40. doi: 10.1016/j.poly.2011.05.016

Wasa, M., Engle, K. M., and Yu, J. Q. (2009). Pd(0)/PR 3 -catalyzed intermolecular arylation of $\mathrm{sp}^{3}$ C-H bonds. J. Am. Chem. Soc. 131, 9886-9887. doi: $10.1021 /$ ja903573p

Wessjohann, L. A., Brandt, W., and Thiemann, T. (2003). Biosynthesis and metabolism of cyclopropane rings in natural compounds. Chem. Rev. 103, 1625-1648. doi: 10.1021/cr0100188

Wiberg, K. B. (1996). Bent bonds in organic compounds. Acc. Chem. Res. 29, 229-234. doi: 10.1021/ar950207a

Wu, Y. W., Chen, Y. Q., Liu, T., Eastgate, M. D., and Yu, J. Q. (2016). Pd-catalyzed $\gamma-\mathrm{C}\left(\mathrm{sp}^{3}\right)-\mathrm{H}$ arylation of free amines using a transient directing group. J. Am. Chem. Soc. 138, 14554-14557. doi: 10.1021/jacs.6b09653

Xie, H., Zu, L., Li, H., Wang, J., and Wang, W. J. (2007). Organocatalytic enantioselective cascade michael-alkylation reactions: synthesis of chiral cyclopropanes and investigation of unexpected organocatalyzed stereoselective ring opening of cyclopropanes. J. Am. Chem. Soc. 129, 10886-10894. doi: $10.1021 /$ ja073262a

Xie, H. J., Fan, T., Lei, Q. F., and Fang, W., J. (2016). New progress in theoretical studies on palladium-catalyzed C-C bond-forming reaction mechanisms. Sci. China Chem. 59, 1432-1447. doi: 10.1007/s11426-016-0018-2

Xie, H. J., Lin, F. R., Lei, Q. F., and Fang, W. J. (2013b). Mechanism and substratedependent rate-determining step in palladium-catalyzed intramolecular 
decarboxylative coupling of arenecarboxylic acids with aryl bromides: a DFT study. Organometallics 32, 6957-6968. doi: 10.1021/om400503x

Xie, H. J., Zhang, H., and Lin, Z. Y. (2013a). DFT studies on the palladiumcatalyzed dearomatization reaction between chloromethylnaphthalene and the cyclic amine morpholine. Organometallics 32, 2336-2343. doi: $10.1021 / 0 m 301215$ a

Xie, H. J., Zhang, H., and Lin, Z. Y. (2013c). DFT studies on the mechanisms of palladium-catalyzed intramolecular arylation of a silyl $\mathrm{C}\left(\mathrm{sp}^{3}\right)-\mathrm{H}$ bond. $\mathrm{N}$. J. Chem. 37, 2856-2861. doi: 10.1039/c3nj00531c

Xuan, Y., Nie, S., Dong, L., Zhang, J., and Yan, M. (2009). Highly enantioselective synthesis of nitrocyclopropanes via organocatalytic conjugate addition of bromomalonate to $\alpha, \beta$-unsaturated nitroalkenes. Org. Lett. 11, 1583-1586. doi: $10.1021 / \mathrm{ol} 900227 \mathrm{j}$

Zhao, Y., and Truhlar, D. G. (2006a). Comparative DFT study of van der waals complexes: rare-gas dimers, alkaline-earth dimers, zinc dimer, and zinc-raregas dimers. J. Phys. Chem. A 110, 5121-5129. doi: 10.1021/jp060231d

Zhao, Y., and Truhlar, D. G. (2006b). Density functional for spectroscopy: no longrange self-interaction error, good performance for rydberg and charge-transfer states, and better performance on average than B3LYP for ground states. J. Phys. Chem. A 110, 13126-13130. doi: 10.1021/jp066479k
Zhao, Y., and Truhlar, D. G. (2008). The M06 suite of density functionals for main group thermochemistry, thermochemical kinetics, noncovalent interactions, excited states, and transition elements: two new functionals and systematic testing of four M06-class functionals and 12 other functionals. Theor. Chem. Acc. 120, 215-241. doi: 10.1007/s00214-007-0310-x

Zhu, R. Y., Li, Z. Q., Park, H. S., Senanayake, C. H., and Yu, J. Q. (2018). Ligandenabled $\gamma-\mathrm{C}\left(\mathrm{sp}^{3}\right)-\mathrm{H}$ activation of ketones J. Am. Chem. Soc. 140, 3564-3568. doi: $10.1021 /$ jacs.8b01359

Conflict of Interest Statement: The authors declare that the research was conducted in the absence of any commercial or financial relationships that could be construed as a potential conflict of interest.

Copyright (๑) 2019 Ying, Zhang, Xiang, Song, Xie and Bao. This is an open-access article distributed under the terms of the Creative Commons Attribution License (CC $B Y)$. The use, distribution or reproduction in other forums is permitted, provided the original author(s) and the copyright owner(s) are credited and that the original publication in this journal is cited, in accordance with accepted academic practice. No use, distribution or reproduction is permitted which does not comply with these terms. 